\title{
DELIRIUM AFTER CARDIAC SURGERY: A CRITICAL REVIEW
}

\author{
ROSE C. VAN DER MAST* and FRITS H. J. ROEST $\dagger$
}

(Received 4 December 1995; accepted 12 January 1996)

\begin{abstract}
Numerous articles have been published investigating the incidence of and risk factors for delirium after cardiac surgery. Smith and Dimsdale reviewed the literature on postcardiotomy delirium in 1987 using a meta-analysis of 44 research studies. However, doubts about their methods and results caused the authors to re-examine the literature using these 44 references as well as computerized literature searches to gather research and review papers from medical journals. Delirium after cardiac surgery appeared to be ill-defined in most of these studies. The methods and instruments used to assess delirium proved to be very different, and the patient samples were rather heterogeneous. Therefore, in most cases, the results are not comparable. Only a small number of the studies that were examined fit the criteria for statistical meta-analysis. On the basis of our analysis, a tentative conclusion may be drawn that the incidence of postcardiotomy delirium has declined slightly and that no strong risk factors have yet been identified.
\end{abstract}

Keywords: Cardiac surgery; Delirium; Incidence; Meta-analysis; Review; Risk factors.

\section{INTRODUCTION}

Since the mid-1950s numerous articles have been published concerning psychiatric complications, especially delirium, following cardiac surgery [1-57]. Cardiac surgery has traditionally been associated with a particularly high rate of postoperative delirium. The reported incidence varies from $2 \%$ to $57 \%$, depending on the research design, the selection of patients, the type of cardiac surgery, the assessment methods and, not least of all, the criteria and definition of delirium [1-57, see Table I].

Blachly and Starr [5] were the first to use the term postcardiotomy delirium for delirium after cardiac surgery. They defined delirium as a syndrome consisting of impairment of orientation, memory, intellectual function and judgment, and emotional lability. Originally, postcardiotomy delirium was associated with open-heart surgery, but later on the term was also used for delirium after coronary artery bypass surgery, even though, unlike an operation to repair valvular and congenital defects, this procedure does not require the heart to be opened extensively [31]. This has meant less likelihood of cardiac damage and of a (micro)embolization, a possibly important insult to the brain. However, since postcardiotomy delirium is an established diagnos-

* Department of Psychiatry, University Hospital-Dijkzigt.

† Center for Clinical Decision Sciences, Department of Public Health, Erasmus University, Rotterdam, The Netherlands.

Address correspondence to: Mrs. R. C. van der Mast, MD,PhD, Dept. of Psychiatry, University Hospital, Rotterdam, Dr. Molewaterplein 40, 3015 GD Rotterdam, The Netherlands; Tel: (0) 10-4639222; Fax: (0)10-4633217. 


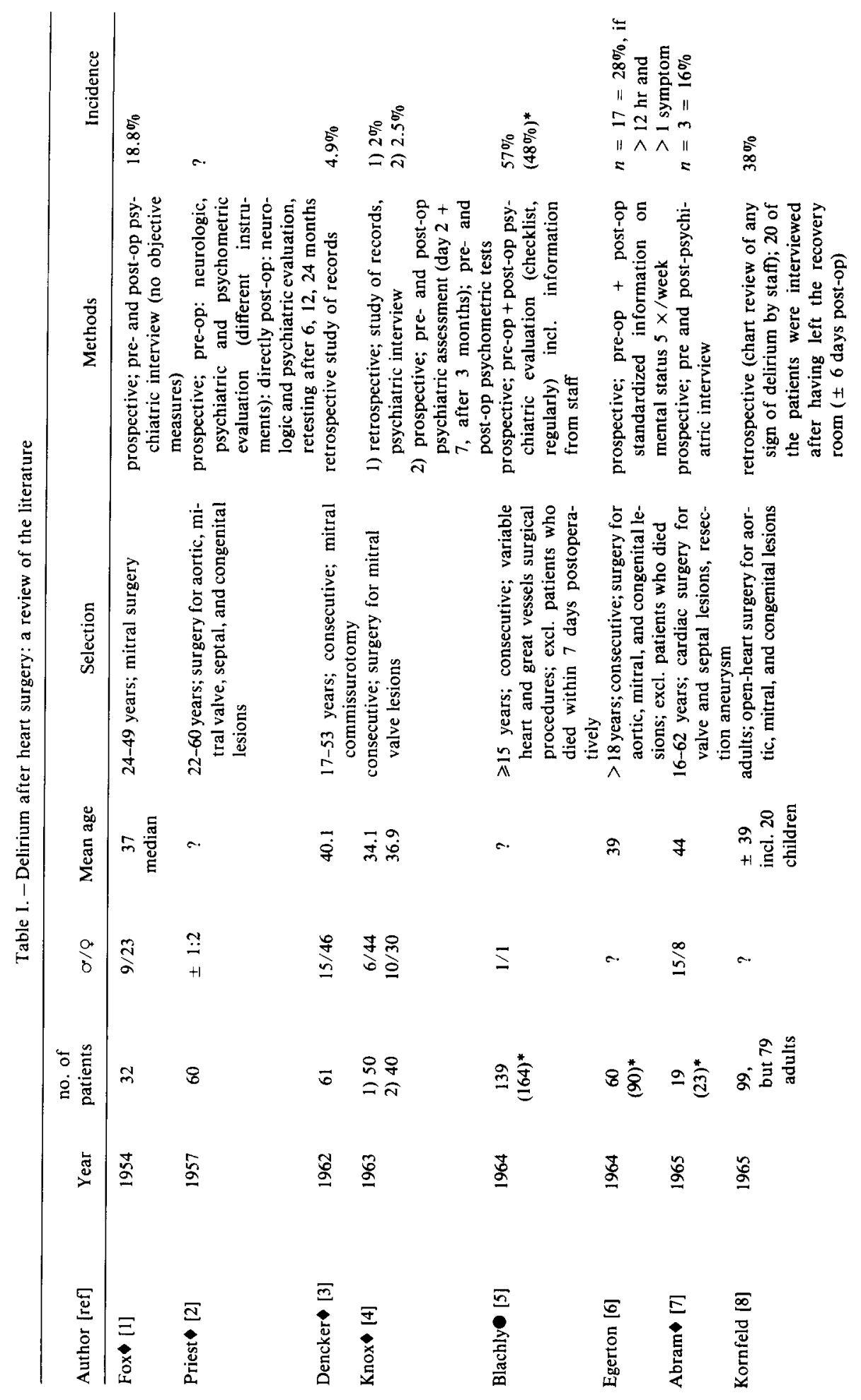




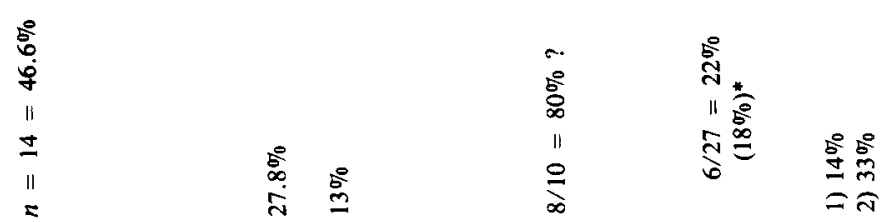

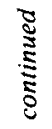

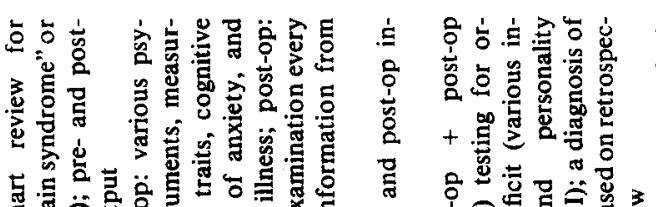

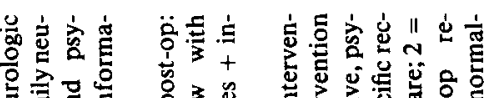

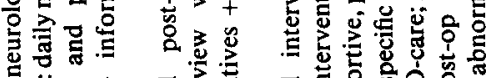

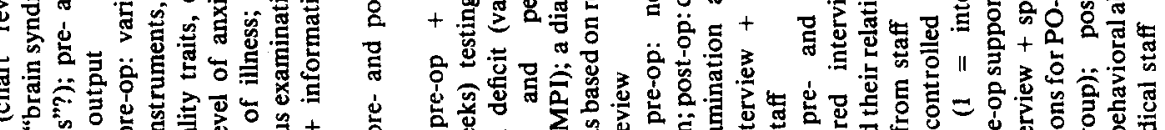

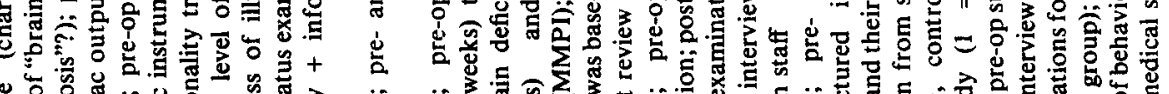

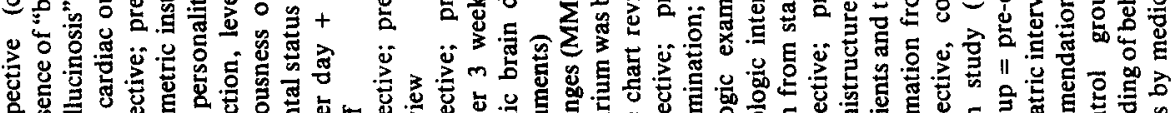

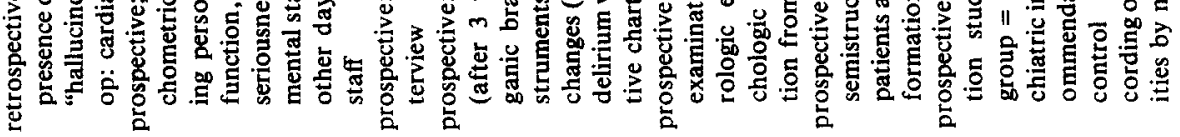
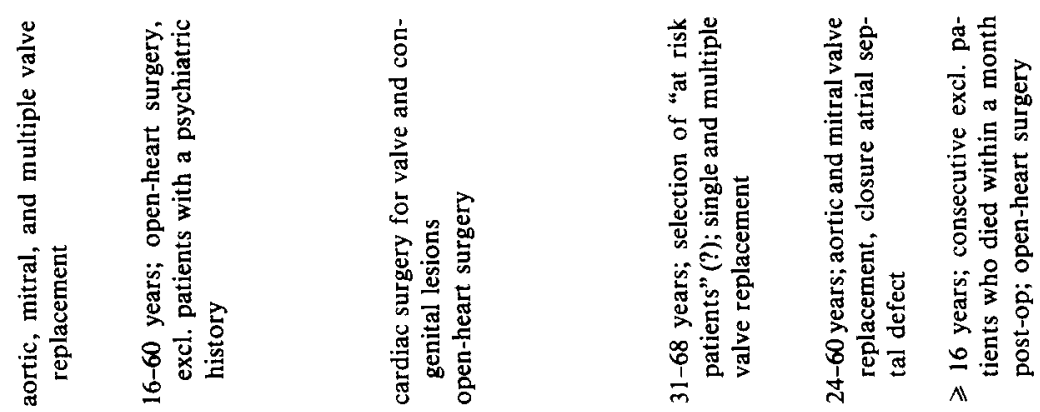

a. $\quad \stackrel{m}{*}$

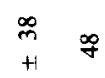

$\stackrel{2}{2} \stackrel{0}{\frac{\pi}{2}}$

$\stackrel{\infty}{\frac{\pi}{\omega}}$

m

ก

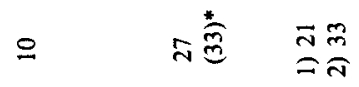

$\stackrel{2}{2}$

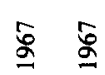

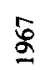

$\stackrel{\infty}{\circ}$
$\frac{5}{5}$

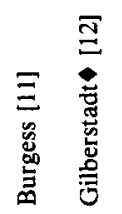

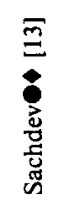

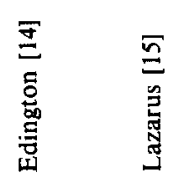




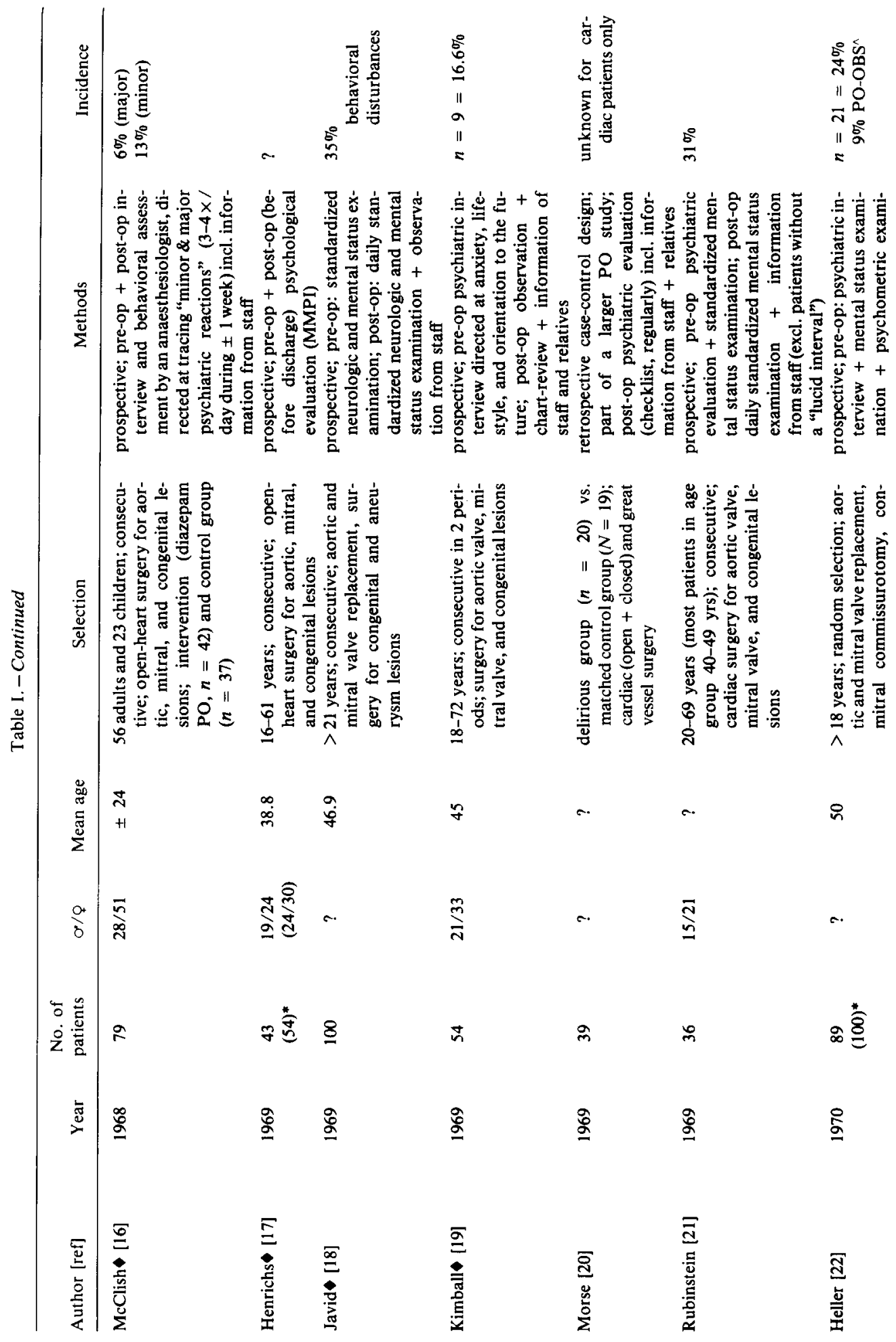




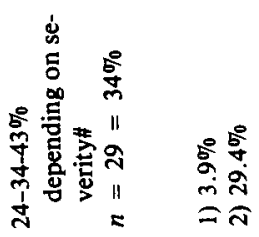

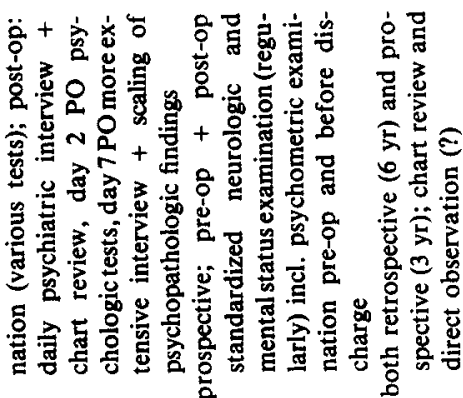
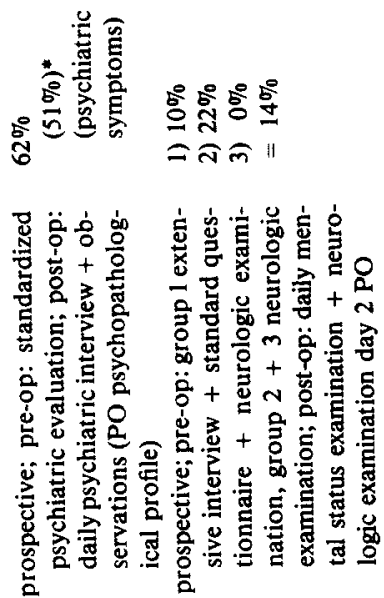
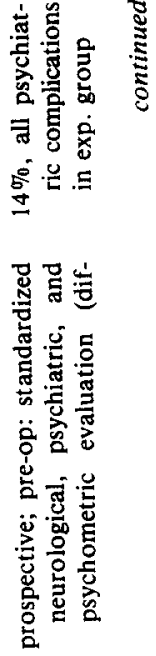

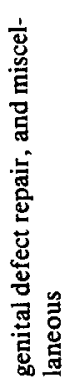

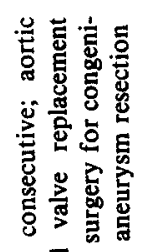

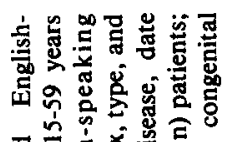

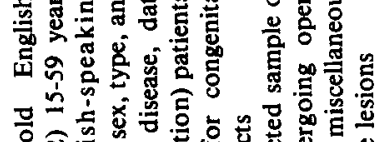

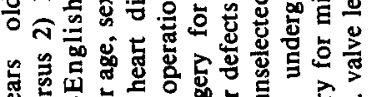

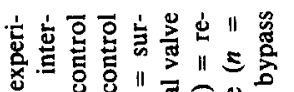

害言

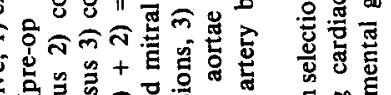

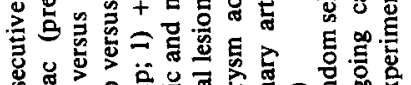

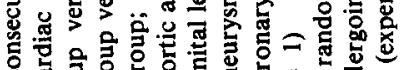

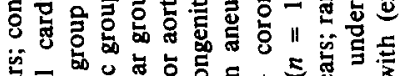

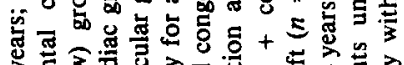

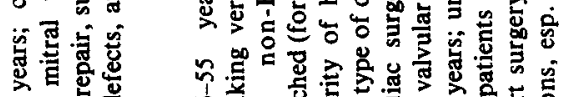

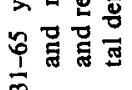

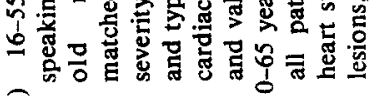

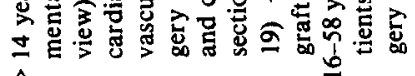

\begin{tabular}{|c|c|c|c|}
\hline$r$ & 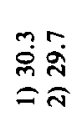 & $q$ & 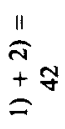 \\
\hline ஜூ & 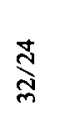 & సิ & 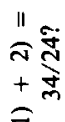 \\
\hline
\end{tabular}

$\infty \stackrel{*}{8}$

$\stackrel{゚}{\stackrel{\circ}{2}}$

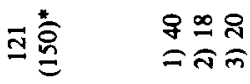

$\infty$

옹

5

포

$\bar{\Xi}$

$\underline{5}$

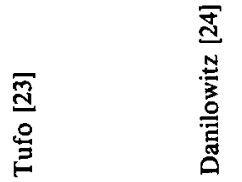

高

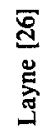

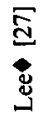




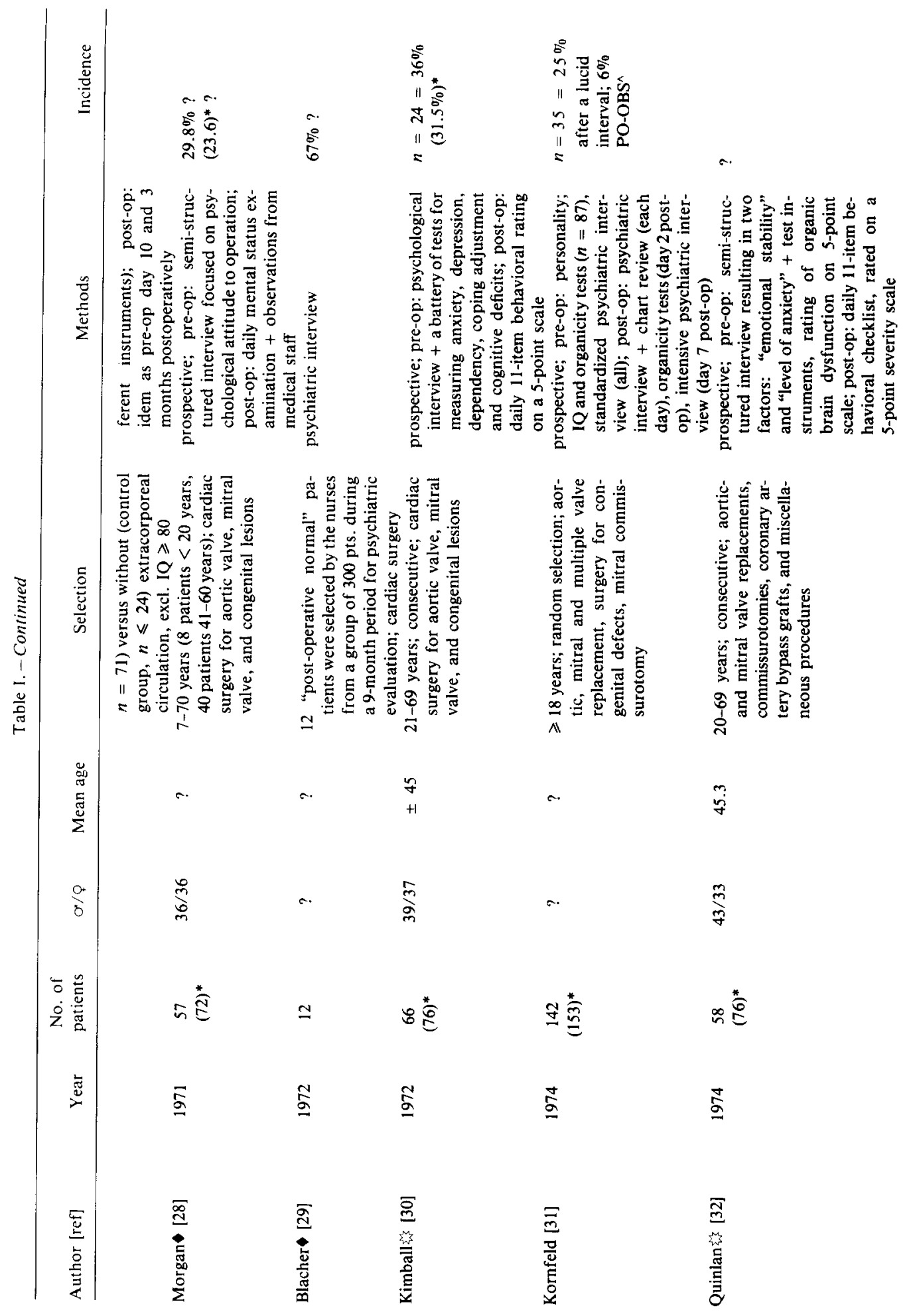




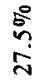

"오요

ニ

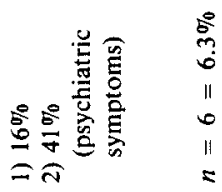

$\stackrel{0}{50}$

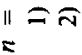

a.

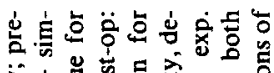

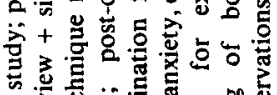

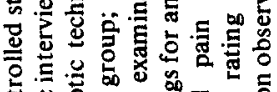

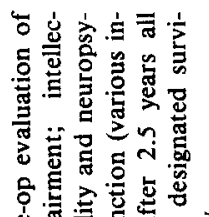

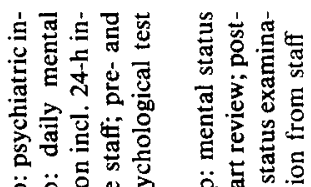
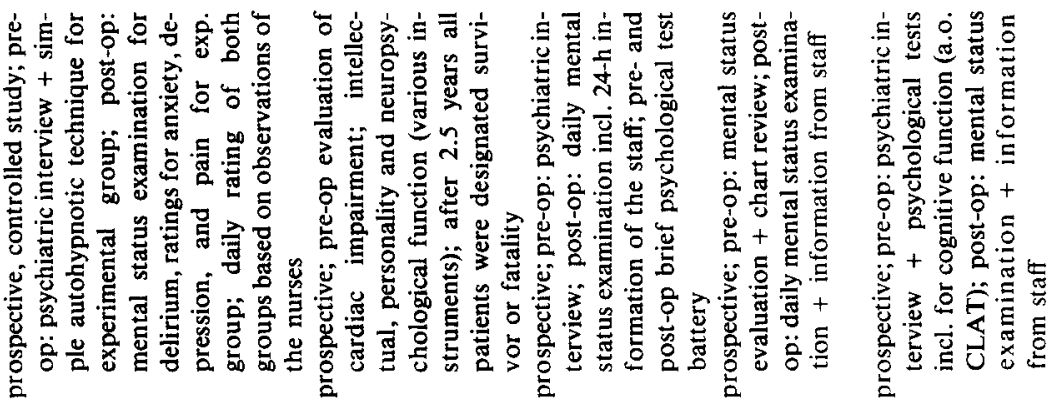

is

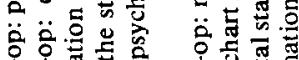

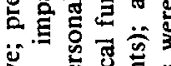

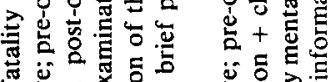

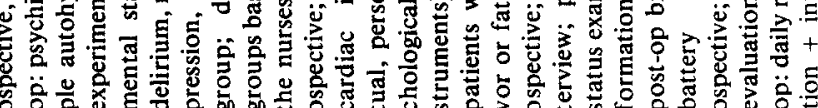

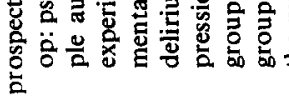
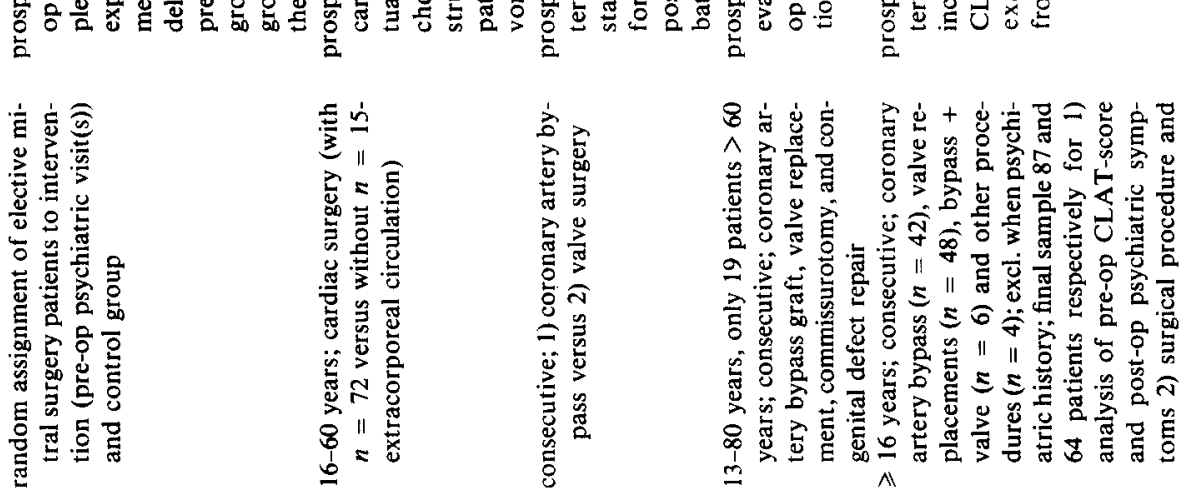

ํํำ

$\approx$

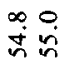

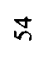

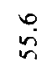

$\sum_{6} \underset{2}{2}$

$\underset{\substack{\text { \} \\ \text { } }}{ }$

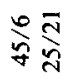

$\sum_{\infty}^{\infty}$

s

융ำ

$\infty$

ㄷํㄴำ

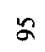

8

点

$\stackrel{n}{5}$

$\stackrel{5}{5}$

$\frac{n}{5}$

5

$\frac{\sqrt[n]{m}}{\stackrel{5}{E}}$

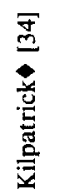

离

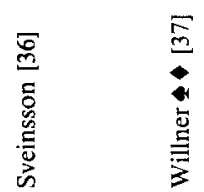


R. C. VAN DER MAST and F. H. J. ROEST

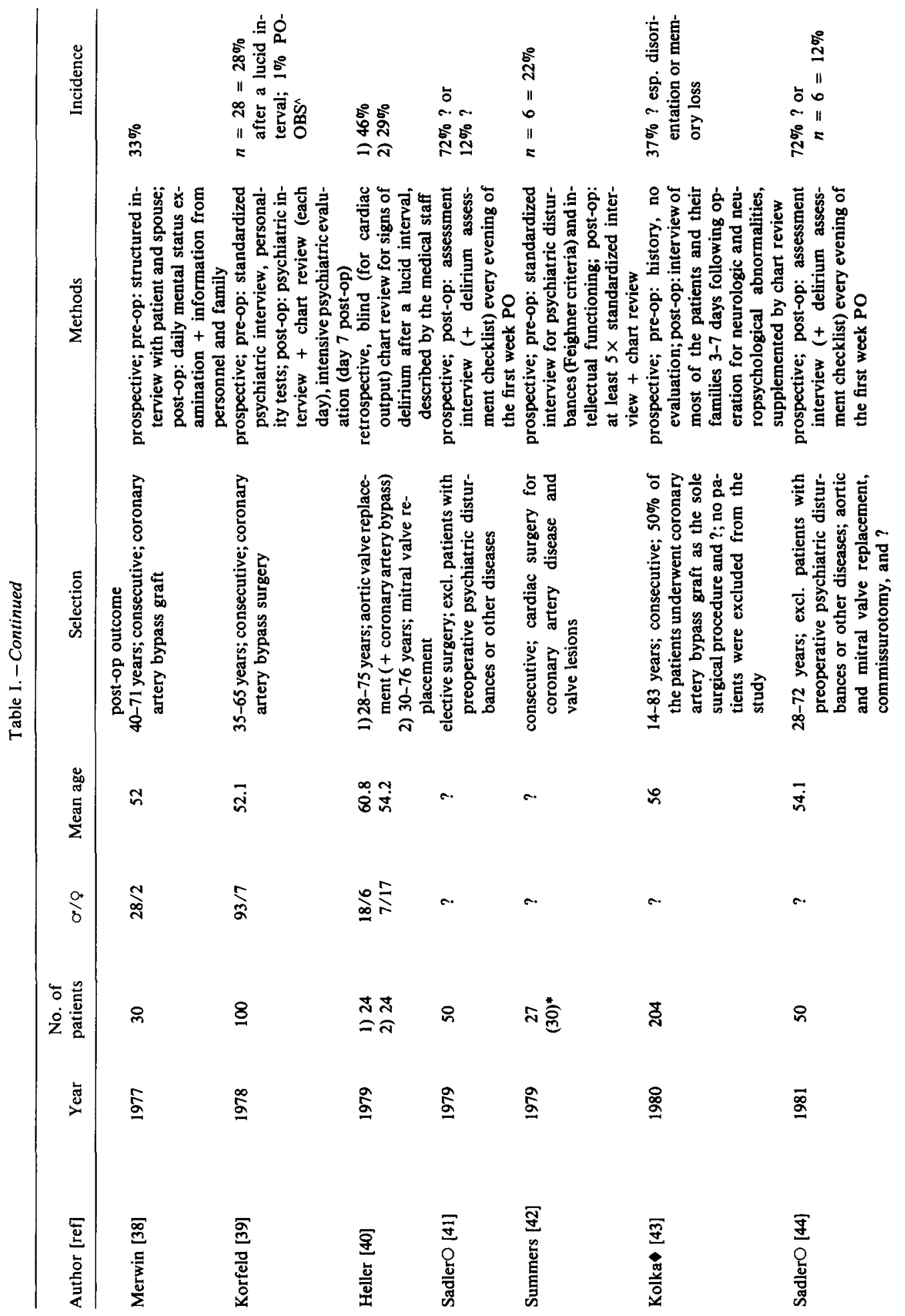



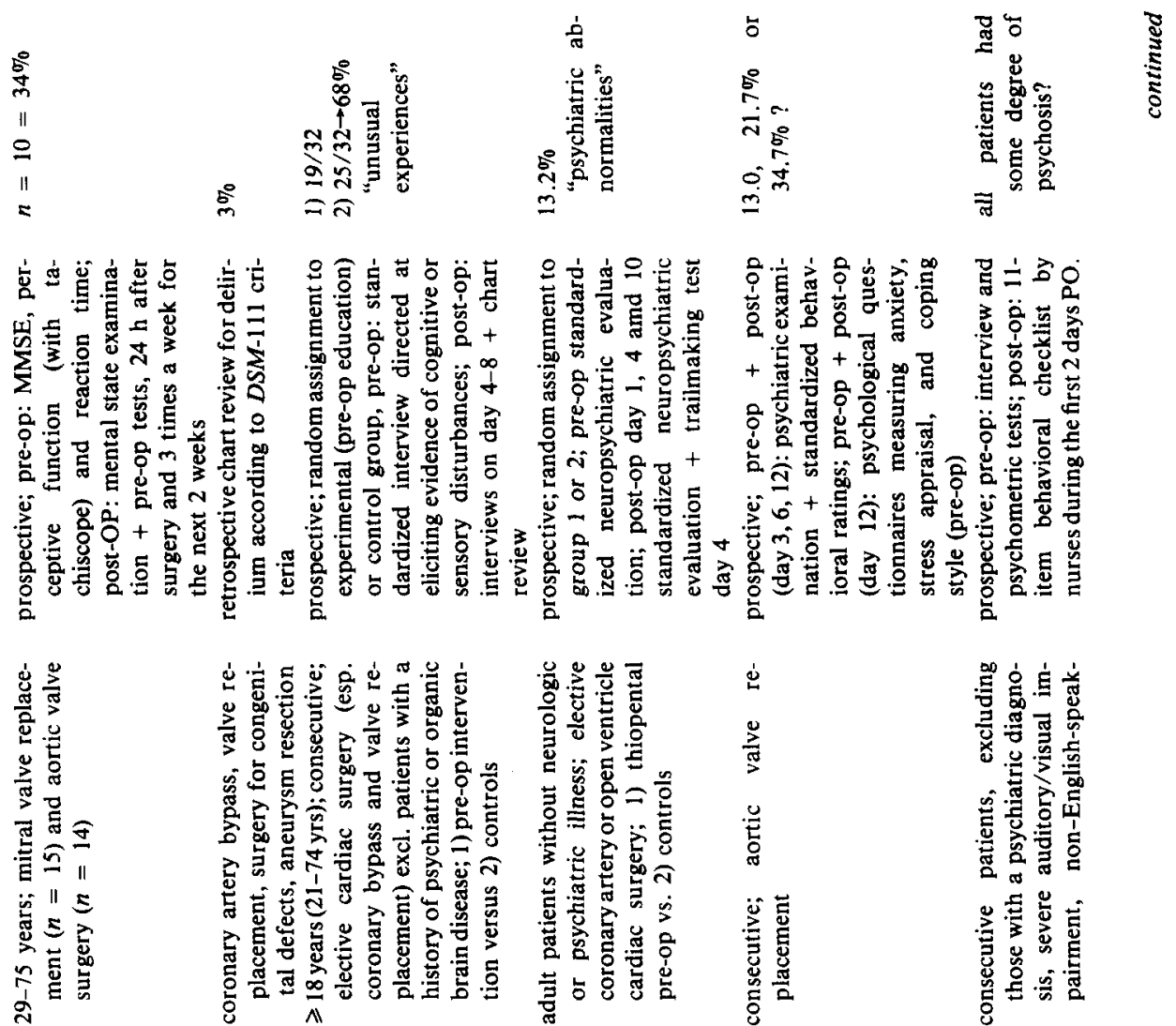

$\approx$

in

它莣

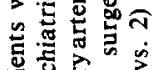

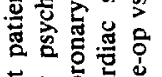

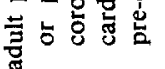

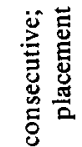

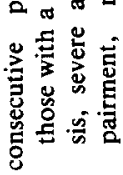

$\stackrel{N}{I}$

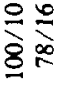

$\frac{8}{\bar{\pi}}$

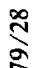

$\frac{n}{n}$

2

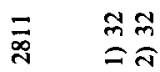

$\varrho$
$\triangleq$

$2 \stackrel{*}{\stackrel{0}{\complement}}$

인

ळ $\stackrel{\cong}{\circ}$

$\stackrel{\infty}{\sigma}$

$\stackrel{\circ}{\circ}$

$\stackrel{\wp}{\varrho}$

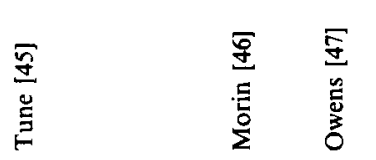

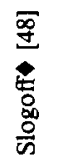

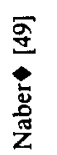

$\frac{\bar{h}}{\frac{0}{6}}$ 


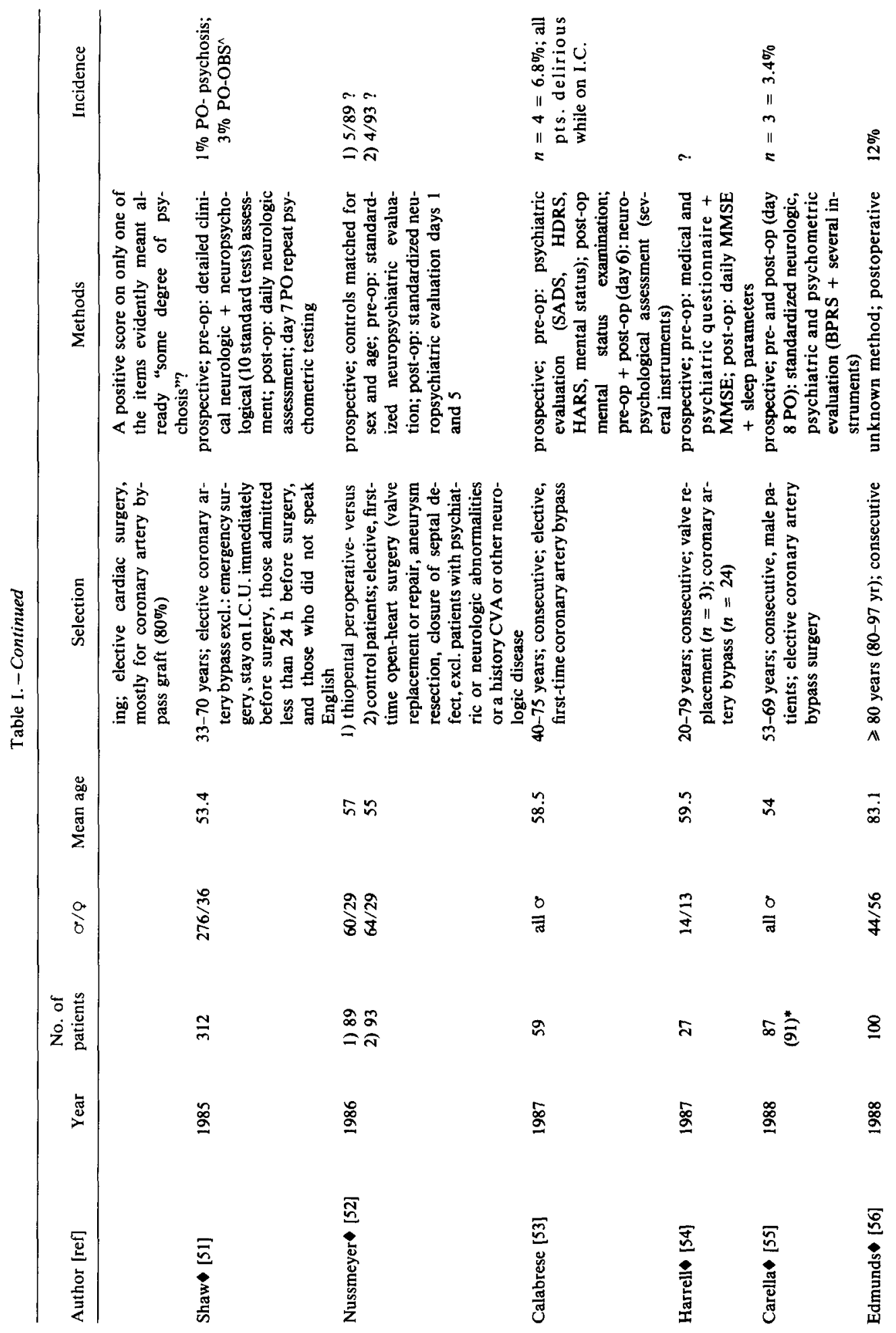




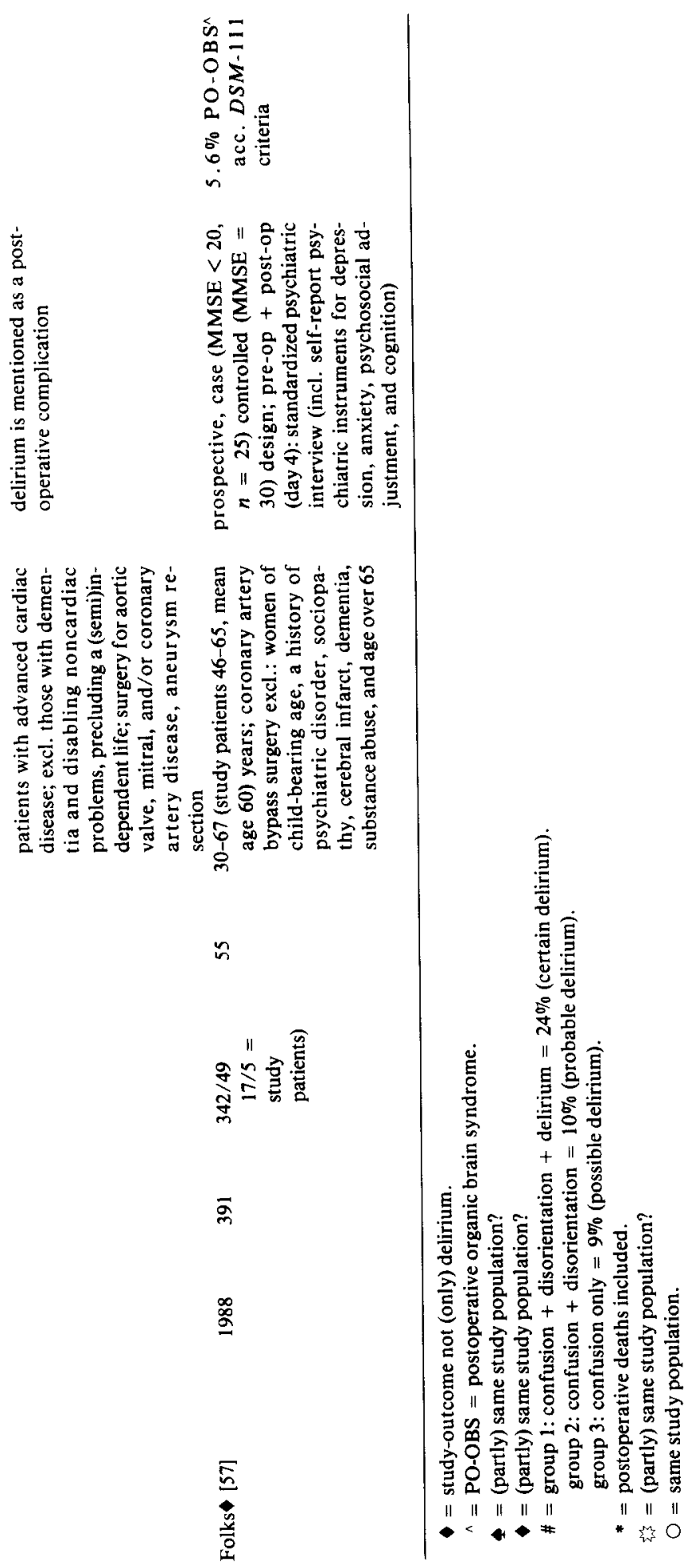


tic term, we will use it for delirium after cardiac surgery, irrespective of the kind of operation.

The current incidence of postcardiotomy delirium is unknown, and multiple studies have implicated as many risk factors. Smith and Dimsdale [59] reviewed the literature using a meta-analysis of 44 research studies, which were published between 1963 and 1987 in a variety of English-language journals. They examined the incidence of postcardiotomy delirium and the relationship with 28 hypothesized risk factors, concluding that the incidence has remained fairly constant over time at $32 \%$ [59]. Apart from incidence of preoperative psychiatric intervention, they did not find any significant correlation between the occurrence of postcardiotomy delirium and any other risk variable. However, after reviewing the studies used in the meta-analysis, comment can be made on their methods and conclusions.

One of the main problems is the definition of delirium. According to current diagnostic standards, the DSM-IV [60], and ICD-10 [61], the essential features of delirium are: a) clouding of consciousness with reduced ability to focus, sustain, or shift attention, and b) changes in cognition (such as memory deficit, disorientation, language disturbance, perceptual disturbance). The syndrome may also involve c) disturbance of the sleep-wake cycle or level of psychomotor activity and d) a relatively rapid onset and a course that typically fluctuates. The total duration is usually brief about one week. Although it is, of course, impossible to classify all of the research studies according to current diagnostic criteria, an effort has to be made to meet these current criteria as far as possible.

Smith and Dimsdale classified "the various clinical presentations" of postcardiotomy delirium into 3 groups: group 1 consisted of symptoms of disorientation about place or time, group 2 included perceptual illusions, failure to recognize family or friends, or disorientation about identity, and group 3 contained hallucinations, paranoid delusions, or agitation [59]. However, such a classification represents not the "various clinical presentations," but rather different symptoms of delirium. None of these separate symptoms, as described in the 3 groups is, nowadays, enough for a diagnosis of delirium [60-61].

There has also been some debate on the time of onset of postcardiotomy delirium $[58,59]$. Some investigators - Heller and Kornfeld are the leading exponents - favor a diagnosis of postcardiotomy delirium only when the syndrome follows a lucid postoperative interval of 2 to 5 days $[5,8,22,31,39,40]$. A similar syndrome, occurring before that time interval, is classified as an organic brain syndrome. Other researchers did not find such a "lucid interval" or did not even mention the time of onset as a possibly important clinical feature of delirium after heart surgery [59]. Also, in some studies, but only partly or not at all in others, postoperative deaths were excluded resulting in a different incidence of postoperative delirium.

Since it appeared to be impossible to classify the psychiatric symptoms in most studies - some studies do not even define postoperative delirium, we were puzzled by the methods the authors used to group all 44 studies in as many as 3 categories. Most of the reported studies cannot be used in a meta-analysis, which is a quantative method for reviewing reported studies, because it requires at the very least, well defined, discrete endpoints, that is, delirium [61]. The conclusion that the incidence of delirium has remained fairly constant over time is therefore questionable.

A further problem is the selection of patients in the studies included in the meta- 
analysis [59]. Studies using consecutive and selected patient samples of different age ranges, gathered both retrospectively and prospectively by different methods of case finding, that is, interview or chart review, were taken together (Table I). Also, the type of cardiac surgery studied shifted from surgery for valve and congenital lesions in the ' 60 s and early '70s to mainly coronary artery bypass surgery (with or without valve replacement) in the late ' 70 s and ' 80 s. Consequently, the patient samples changed with respect to, for example, distribution of gender and age, surgical procedures, and duration of extracorporeal circulation [Table I]. While surgery for valve and congenital lesions was performed mainly on female patients, coronary artery bypass surgery was performed predominantly on male patients. Moreover, the mean age increased approximately 10 years over time.

Smith and Dimsdale used the vote-counting method described by Hedges and Olkin $[62,63]$ to estimate the underlying population correlation between a risk factor and the incidence of postcardiotomy delirium from the collection of selected studies. Although vote counting is appropriate when the only information available is whether a relationship was reported to be significant, it yields a very crude estimate of the population correlation. Therefore, confidence intervals should always be added. To be able to draw any reliable conclusions, at least 10 studies are needed [63]. In the meta-analysis done by Smith and Dimsdale [59], this was the case for only age, gender, and time on cardiopulmonary bypass. For example, if 3 studies are available describing the relationship between preoperative psychiatric intervention and postcardiotomy delirium [59], only 3 correlation estimates are possible: 0 when none or one of the 3 studies reports a significant relation, 0.06 when 2 studies report a significant relation, and 0.60 when all 3 studies report a significant relation. In the last case, the $95 \%$ confidence interval for 0.60 ranges from 0 to 1 (only positive correlations are estimated). This means that the population correlation can be anything from nonexistent to perfect. This clearly demonstrates the need for sufficient studies reporting on a possible risk factor.

This leads to the problem of the power of the studies examined. The sample sizes are usually small, varying from 10 to 312 , with only 6 out of 44 studies describing a sample size larger than 100 [59]. In a sample of 100 cases, a sample correlation has to be larger than 0.20 to be significant. In a complex syndrome like postcardiotomy delirium, the correlation between a risk factor and the event may typically be lower than 0.20 or, in terms of odds ratios, the relative risk may be lower than 1.5.

Another problem is the publication bias. Nonsignificant results are either not reported at all or the test results are not given. For example, most studies will have at least recorded the age and gender of their patients and, in most cases, have tested for a significant relationship. Nevertheless, in many studies not even the mean age and/or gender distribution are reported.

All of these circumstances make it, in our opinion, impossible to group the different studies on delirium after cardiac surgery together for a meta-analysis as reported by Smith and Dimsdale [59]. Consequently, their conclusion that the incidence of postcardiotomy delirium has remained fairly constant over time at $32 \%$ and that, of all the surveyed risk factors, only preoperative psychiatric intervention correlated substantially with postcardiotomy delirium, is unfounded. Therefore, we selected those studies on postcardiotomy delirium in which delirium was well defined and more or less comparable to current criteria $[60,61]$ and examined the possibilities for further analysis of incidence and risk factors. 


\section{METHODS}

The 44 research studies analyzed by Smith and Dimsdale $[4-6,8-16,18,21-31,33,35-45,47-54]$ were investigated. A literature search was done for the period between 1988 and 1994, yielding 3 more studies on postcardiotomy delirium [55-57]. Another 10 studies, reporting on the relation between cardiac surgery and the occurrence of postoperative delirium $[1-3,7,17,19,20,32,34,46]$, not used by Smith and Dimsdale, were found in the references. From those studies using (partly) the same study sample, the most adequate (e.g., the one used by Smith and Dimsdale) and detailed one was taken for further examination. Those studies in which postcardiotomy delirium was well defined and more or less met the current diagnostic criteria $[60,61]$ were selected. For example, Heller and Kornfeld $[8,22,31,39$, 40] judged patients to have a delirium when, after a lucid interval of 2 to 5 days, they developed illusions, frequently accompanied by difficulty in distinguishing between dreams and reality, of ten with disorientation and sometimes prog. ressing to hallucinations and delusions. This definition was considered adequate, even though attentional disorder and disorganized thinking in the narrow sense were lacking and the necessity of a "lucid interval" after surgery was introduced. Studies that mentioned "organic brain syndromes" to classify delirium-like and/or neurological symptoms $[22,31,39,51]$ were not included because it was impossible to distinguish "true" postcardiotomy delirium.

Retrospective studies in which delirium was well defined were examined separately. Studies reporting on selected patient samples were excluded as well as patient samples that had been gathered both retrospectively and prospectively without specifying where the data came from. In one study, we excluded children younger than 16 years, using only information from adult patients [36]. The selected studies were scrutinized and, as far as possible, analyzed for incidence and risk factors for postcardiotomy delirium.

\section{RESULTS}

Most, namely, 28 of the 44 studies used by Smith and Dimsdale for analysis of the overall incidence, did not describe delirium at all or did not do so sufficiently enough to draw any conclusions $[4,5,9,11,12-16,18,21,25-29,35,37,38,41,43,47-52$, 54]. In 16 studies, postcardiotomy delirium was rather well defined $[6,8,10,22-24$, $30,33,36,39,40-42,44,45,53]$. These studies were supplemented with an adequately defined study published after 1987 [55] and 2 (of the 10) studies found in the literature $[7,19]$. An overview of all the studies is shown in Table I. Four pairs of studies apparently used (partly) the same patient sample [5/13, 30/32, 35/37, and 41/44]. Only 2 pairs of studies [30/32 and $41 / 44$ ] used well-defined criteria, from which the most adequate ones were chosen for further examination [30, 44]. Six studies that used selected patient samples or samples gathered both retrospectively and prospectively were excluded $[15,21,24,29,47,56]$. This yielded a total of 16 prospective $[6,10,17,19,22,23,30,33,36,39,40,42,44,45,53,55]$ and 3 retrospective $[8,40$, 46] studies for further research and analysis of the overall incidence of postcardiotomy delirium and possible risk factors.

Figure 1 shows the incidences of delirium reported in the 16 prospective and 3 retrospective selected studies. For each incidence, the confidence interval was computed based on the sample size of the study. The incidences vary considerably, and the small overlap of the confidence intervals is a clear sign of the heterogeneity of the studies. This means that not all samples are drawn from the same population. An important assumption for statistical meta-analysis is therefore not met. Regression analysis was used to test the hypothesis that this heterogeneity is due to reported differences between the studies, such as, year of publication, type of surgery, mean age, and gender distribution. Although the heterogeneity of the patient samples could not be explained, a significant relationship was found between year of publication and incidence of postcardiotomy delirium $(p=0.02)$, the later publications showing a tendency towards a lower incidence. Since there were only 3 retrospective studies, only incidences and confidence intervals can be given (see Fig. 1). The large discrepancy 


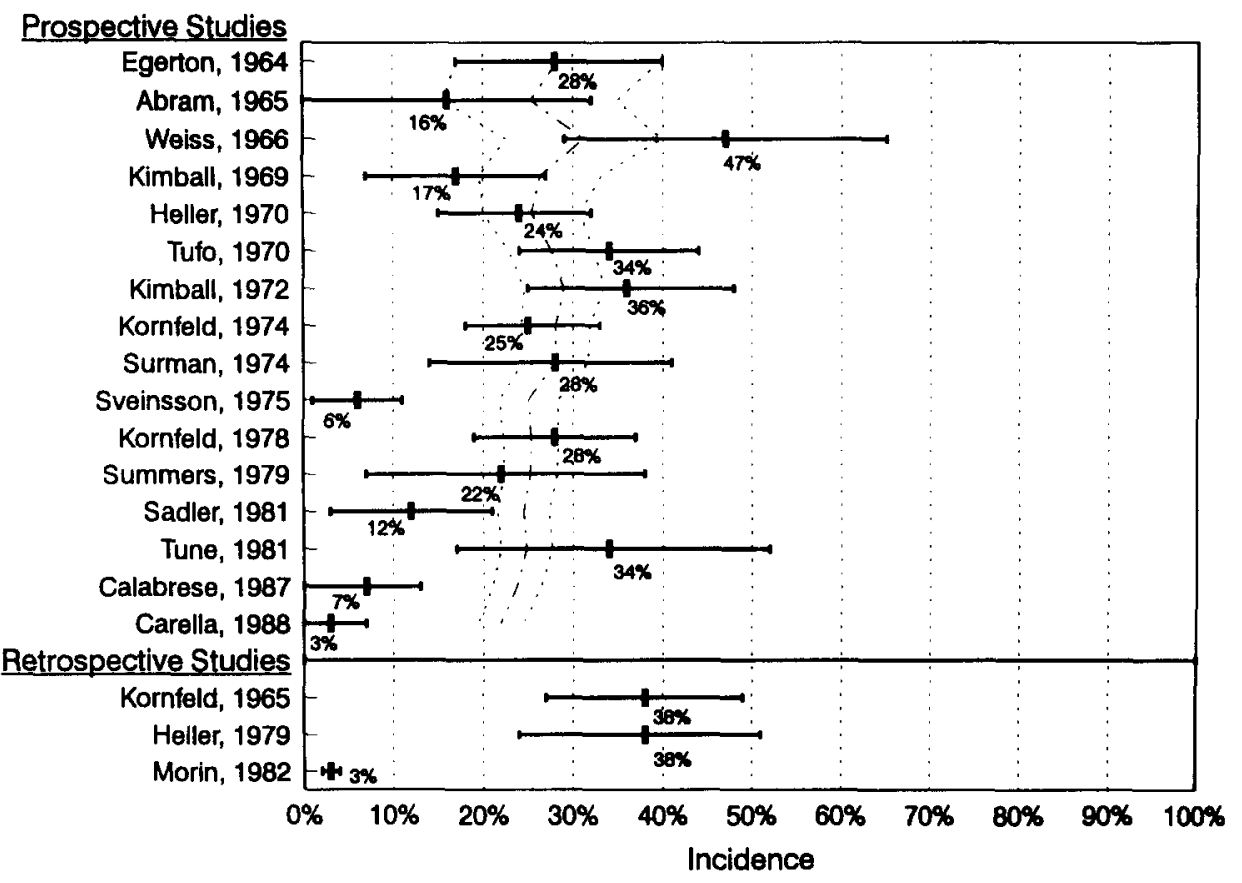

Fig. 1. Incidences, confidence intervals and cumulative confidence intervals (dotted lines) of delirium after cardiac surgery.

between, on the one hand, the studies of Kornfeld [8] and Heller [40] and, on the other hand, Morin [46] is explained by the different methods used and the sample sizes (Table I).

Even though results on the effect of the possible risk factors of age, gender, and time on cardiopulmonary bypass were reported frequently enough, we decided not to perform a statistical meta-analysis, since the assumption of homogeneity was not met.

\section{DISCUSSION}

Even after 30 years and more than 50 studies addressing in some way the issues of incidence of and risk factors for delirium after cardiac surgery, these questions remain unanswered. A few reasons for this can be pointed out. First of all, since the criteria have evolved over time, delirium is not equally defined in the studies reporting on postcardiotomy delirium or, even worse, is not defined at all. This makes it difficult to compare the various studies. For example, of the 29 studies having postoperative delirium as the most important outcome measure, $12(41 \%)$ studies do not use an adequate definition of delirium.

An important unresolved and difficult issue in this respect is the operationalization of the diagnostic criteria to ensure reliability and replicability of research findings [64]. In none of the described studies are the criteria for postoperative delirium explicitly operationalized. Second, consecutive patient samples appear to be no guar- 
antee of homogeneity of the various studies. Other factors probably influence the incidence: the kind of hospital, the area served, the number of beds, the experience of the surgeons, and the inclusion and exclusion criteria used. These were often not sufficiently specified.

Of all the reported differences in the studies, only year of publication is significantly related to the incidence of delirium after cardiac surgery, the later publications showing a tendency towards a lower incidence. In contrast to the conclusion of Smith and Dimsdale, this may be in line with the clinical notion that the incidence of postcardiotomy delirium has declined, possibly due to improved surgical and cardiopulmonary bypass techniques.

Furthermore, it is hard to judge the statistical merits of the studies when the data and statistical techniques are insufficiently described. An example of poor statistical quality is the article of Tufo et al. [23]. They report the relationship between cerebral damage and age groups to be highly significant, which is not the case if an analysis is made of the frequencies in the Table I. Also, in contrast to the reported result, the relation between cerebral damage and blood pressure during bypass appears to be significant. In general, the statistical results could not be reproduced from the reported data. This seriously hampers statistical meta-analysis.

In conclusion, most of the results of the studies reporting on postoperative delirium after cardiac surgery are not comparable. Nevertheless, a cautious conclusion may be drawn that no strong risk factor has been identified and that the incidence of postcardiotomy delirium has probably decreased.

\section{REFERENCES}

1. Fox Hm, Rizzo Nd, Gifford S. Psychological observations of patients undergoing mitral surgery. Psychosom Med 1954;16:186-208.

2. Priest WS, Zaks MS, Yacorzynski GK, Boshes B. The neurologic, psychiatric, and psychologic aspects of cardiac surgery. Med Clin North Am 1956;41:155-69.

3. Dencker SJ, Sandahl A. Major mental disturbances in a series of patients surgically treated for mitral stenosis. Acta Psychiatr Scand 1962;38:117-23.

4. Knox SJ. Psychiatric aspects of mitral valvotomy. Br J Psychiatry 1963;109:656-68.

5. Blachly PH, Starr A. Post-cardiotomy delirium. Am J Psychiatry 1964;121:371-375.

6. Egerton N, Kay JH. Psychological disturbance associated with open-heart surgery. Br J Psychiatry 1964;110:443-9.

7. Abram HS. Adaptation to open heart surgery: a psychiatric study of response to the threat of death. Am J Psychiatry 1975;122:659-67.

8. Kornfeld DS, Zimberg S, Malm JR. Psychiatric complications of open-heart surgery. N Engl J Med 1965;273:287-92.

9. Blachly PH, Kloster FE. Relation of cardiac output to postcardiotomy delirium. J Thorac Cardiovasc Surg 1966;52:422-7.

10. Weiss SM. Psychological adjustment following open-heart surgery. J Nerv Ment Dis 1966;143:363-8.

11. Burgess GN, Kirklin JW, Steinhilber RM. Some psychiatric aspects of intracardiac surgery. Mayo Clin Proc 1967;42:1-12.12. Gilberstadt H, Sako Y. Intellectual and personality changes following open-heart surgery. Arch Gen Psychiatry 1967;16:210-5.

13. Sachdev NS, Carter CC, Swank RL, Blachly PH. Relationship between postcardiotomy delirium, clinicial neurological changes, and EEG abnormalities. J Thorac Cardiovasc Surg 1967;54:557-63.

14. Edington HC. Open-heart surgery: a triple threat. South Med J 1968;61:160-6.

15. Lazarus HR, Hagens JH. Prevention of psychosis following open-heart surgery. Am J Psychiatry 1968;134:1190-5.

16. McClish A, Andrew $D$, Tetreault $L$. Intraveneous diazepam for psychiatric reactions following openheart surgery. Can Anaesth Soc J 1968;15:63-79.

17. Henrichs TF, MacKenzie JW, Almond $\mathrm{CH}$. Psychological adjustment and acute response to open-heart surgery. J Nerv Ment Dis 1969;148:158-64. 
18. Javid H, Tufo HM, Najafi H, Dye WS, Hunter JA, Julian OC. Neurological abnormalities following open-heart surgery. J Thorac Cardiovasc Surg 1969;58:502-9.

19. Kimball CP. Psychological responses to the experience of open heart surgery; 1: Am J Psychiatry 1969;126:96-107.

20. Morse M, Litin EM. Postoperative delirium: a study of etiologic factors. Am J Psychiatry 1969;126: 388-95.

21. Rubinstein D, Thomas JK. Psychiatric findings in cardiotomy patients. Am J Psychiatry 1969;126: 108-17.

22. Heller SS, Frank KH, Malm JR, Bowman FO, Harris PD, Charlton MC, Kornfeld DS. Psychiatric complications to open-heart surgery. N Engl J Med 1970;283:1015-20.

23. Tufo HM, Ostfeld AM, Shekelle R. Central nervous system dysfunction following open-heart surgery. JAMA 1970;212:1333-40.

24. Danilowitz DA, Gabriel HP. Postcardiotomy psychosis in non-English-speaking patients. Psychiatry Med 1971;2:314-20.

25. Freyhan FA, Gianelli S Jr, O'Connell RA, Mayo JA. Psychiatric complications following open heart surgery. Compr Psychiatry 1971;12:181-95.

26. Layne OL, Yudofsky SC. Postoperative psychosis in cardiotomy patients. N Engl J Med 1971;284: 518-20.

27. Lee WH, Brady MP, Rowe JM, Miller WC. Effects of extracorporeal circulation upon behavior, personality, and brain function. Ann Surg 1971;173:1013-23.

28. Morgan DH. Neuro-psychiatric problems of cardiac surgery. J Psychosom Res 1971;15:41 6.

29. Blacher RS. The hidden psychosis of open-heart surgery. JAMA 1972;222:305-8.

30. Kimball CP. The experience of open heart surgery; 3: Toward a definition and understanding of postcardiotomy delirium. Arch Gen Psychiatry 1972;27:57-63.

31. Kornfeld DS, Heller SS, Frank KA, Moskowitz R. Personality and psychological factors in postcardiotomy delirium. Arch Gen Psychiatry 1974;31:249-53.

32. Quinlan DM, Kimball CP, Osborne F. The experience of open-heart surgery. Arch Gen Psychiatry $1974 ; 31: 241-4$.

33. Surman OS, Hackett TP, Silverberg EL, Behrendt DM. Usefulness of psychiatric intervention in patients undergoing cardiac surgery. Arch Gen Psychiatry 1974;30:830-5.

34. Kilpatrick DG, Miller WC, Allain AN, Huggins MB, Lee WH. The use of psychological test data to predict open-heart surgery outcome: a prospective study. Psychosom Med 1975;37:62-73.

35. Rabiner CJ, Willner AE, Fishman J. Psychiatric complications following coronary bypass surgery. J Nerv Ment Dis 1975;160:342-8.

36. Sveinsson IS. Postoperative psychosis after heart surgery. J Thorac Cardiovasc Surg 1975;70:717-25

37. Willner AE, Rabiner CJ, Wisoff BG, Fishman J, Rosen B, Hartstein M, Klein DF. Analogy tests and psychopathology at follow-up after open heart surgery. Biol Psychiatry 1976;11:687-96.

38. Merwin SL, Abram HS. Psychologic response to coronary artery bypass. South Med J 1977;70:153-5.

39. Kornfeld DS, Heller SS, Frank KA, Edie RN, Barsa J. Delirium after coronary artery bypass surgery. J Thorac Cardiovase Surg 1978;76:93-6.

40. Heller SS, Kornfeld DS, Frank KA, Hoar PF. Postcardiotomy delirium and cardiac output. Am J Psychiatry 1979;136:337-9.

41. Sadler PD. Nursing assessment of postcardiotomy delirium. Heart Lung 1979;8:745-50.

42. Summers WK. Psychiatric sequelae to cardiotomy. J Cardiovasc Surg 1979;20:471-5.

43. Kollka R, Hilberman M. Neurologic dysfunction following cardiac operation with low-flow, lowpressure cardiopulmonary bypass. J Thorac Cardiovasc Surg 1980;79:432-7.44. Sadler PD. Incidence, degree, and duration of postcardiotomy delirium. Heart Lung 1981:10:1084-91.

45. Tune LE, Damlouji NF, Holland A, Gardner TJ, Folstein MF, Coyle JT. Association of postoperative delirium with raised serum levels of anticholinergic drugs. Lancet 1981;2:651-3.

46. Morin P, Coupal P. Delirium post-chirurgie cardiaque avec circulation extra-corporelle: aspects cliniques et observations dans un centre spécialisé. Can J Psychiatry 1982;27:31-9.

47. Owens JF, Hutelmyer CM. The effect of preoperative intervention on delirium in cardiac surgical patients. Nurs Res 1982;31:60-2.

48. Slogoff S, Gigis KZ, Keats AS. Etiologic factors in neuropsychiatric complications associated with cardiopulmonary bypass. Anesth Analg 1982;61:903-11.

49. Naber $D$, Bullinger $M$. Neuroendocrine and psychological variables relating to post-operative psychosis after open-heart surgery. Psychoneuro-endocrinology 1985;10:315-24.

50. Quinless FW, Cassese M, Atherton N. The effect of selected preoperative, intraoperative, and postoperative variables on the development of postcardiotomy psychosis in patients undergoing open heart surgery. Heart Lung 1985;14:334-41.

51. Shaw PJ, Bates D, Cartlidge NEF, Heaviside D, Julian DG, Shaw DA. Early neurological complications of coronary artery bypass surgery. Br Med J 1985;291:1384-7. 
52. Nussmeier NA, Arlund C, Slogoff S. Neuropsychiatric complications after cardiopulmonary bypass: cerebral protection by a barbiturate. Anesthesiology 1986:64:165-70.

53. Calabrese JR, Skwerer RG, Gulledge AD, Gill CG, Mullen JD, Rodgers DA, Taylor PC, Golding LA, Lytle BW, Cosgrove DM, Bazarel MG, Loop FD. Incidence of postoperative delirium following myocardial revascularization. Cleve Clin J Med 1987;54:29-32.

54. Harrell RG, Othmer E. Postcardiotomy confusion and sleep loss. J Clin Psychiatry 1987;48:445-6.

55. Carella F, Traviani G, Contri P, Guzzetti S, Botta M, Pieri E, Mangoni A. Cerebral complications of coronary by-pass surgery: a prospective study. Acta Neurol Scand 1988;77:158-63.

56. Edmunds LH, Stephenson LW, Edie RN, Ratcliffe MB. Open-heart surgery in octogenarians. N Engl J Med 1988;319:131-6.

57. Folks DG, Freeman AM, Sokol RS, Govier AV, Reves JG, Baker DM. Cognitive dysfunction after coronary bypass surgery: a case-controlled study. South Med J 1988;81:202-6.

58. Lipowski ZJ. Delirium: acute confusional states. New York: Oxford University Press; 1990.

59. Smith LW, Dimsdale JE. Postcardiotomy delirium: conclusions after 25 years? Am J Psychiatry 1989; 146:452-8.

60. Diagnostic and statistical manual of mental disorders, 4th ed. Washington: American Psychiatric Association; 1994.

61. The ICD-10 classification of mental and behavioural disorders: clinical descriptions and diagnostic guidelines. Geneva: World Health Organisation; 1992.

62. Greenland S. Quantitative methods in the review of epidemiologic literature. Epidemiologic Reviews 1987;9:1-30.

63. Hedges LV, Olkin I. Statistical methods for meta-analysis. Orlando, Florida: Academic Press; 1985.

64. Levkoff S, Liptzin B, Cleary P, Reilly CH, Evans D. Review of research instruments and techniques used to detect delirium. In: Delirium: advances in research and clinical practice. International Psychogeriatrics 1991;3:253-71. New York: Springer. 